\title{
Initial treatment of complete rotator cuff tear and transition to surgical treatment: systematic review of the evidence
}

\author{
Taiceer A. Abdul-Wahab1 \\ Jean P. Betancourt ${ }^{2}$ \\ Fadi Hassan ${ }^{3}$ \\ Saeed Al. Thani ${ }^{4}$ \\ Hened Choueiri ${ }^{5}$ \\ Nitin B. Jain ${ }^{2}$ \\ Gerard A. Malanga ${ }^{6}$ \\ William D. Murrell ${ }^{7}$ \\ Anil Prasad 8 \\ Olivier Verborgt ${ }^{9}$

\footnotetext{
${ }^{1}$ Mediclinic City Hospital, Dubai, United Arab Emirates

2 Vanderbilt University School of Medicine, Nashville,USA

${ }^{3}$ Hull York Medical School, North Yorkshire, UK

${ }^{4}$ Orthocure Medical Center, United Arab Emirates University, Dubai, United Arab Emirates

${ }^{5}$ Physioart Centre, Dubai, United Arab Emirates

${ }^{6}$ Department of Physical Medicine and Rehabilitation, University of Medicine and Dentistry of New Jersey, USA

${ }^{7}$ Department of Orthopaedic Sports Medicine, Dr. Humeira Badsha Medical Center, Dubai, United Arab Emirates, and Department of Orthopaedics, Rehabilitation, and Pediatry, Ft. Belvoir Community Hospital, Ft. Belvoir, Virginia, USA

${ }^{8}$ Osteopathic Health Centre, Dubai, United Arab Emirates
} \\ ${ }^{9}$ Az Monica Hospital, Antwerp, Belgium
}

Corresponding author:

William D. Murrell

Department of Orthopaedic Sports Medicine,

Dr. Humeira Badsha Medical Center

Beach Road, Jumeirah 2

Dubai, United Arab Emirates

E-mail: doctormurrell@gmail.com

\section{Summary}

Background: rotator cuff tear affects many people. Natural history, and evidence for non-operative treatment remains limited. Our objective is to assess evidence available for the efficacy and morbidity of commonly used systemic medications, physiotherapy, and injections alongside evaluating any negative long-term effects.

\begin{abstract}
Methods: a systematic search was performed of PubMed, Cochrane, EMBASE and CINAHL dates (1 January 1960 - 1 December 2014), search terms: 'rotator cuff tear', 'natural history', 'atraumatic', 'injection', 'physiotherapy'or 'physical therapy', 'injection', 'corticosteroid', 'PRP', 'MSC', risk of conservative treatment', and 'surgical indication'.

Results: eleven studies were included. The mean Coleman Methodology Score modified for conservative therapy is 69.21 (range 88-44) (SD 12.31). This included 2 RCTs, 7 prospective, and 2 retrospective studies. Evidence suggests it is safe to monitor symptomatic rotator cuff tears, as tear size and symptoms are not correlated with pain, function, and/or ultimate outcome.

Conclusions: complete rotator cuff tears may be effectively treated with injections, exercise in the short and intermediate terms respectively. Negative effect of corticosteroids on rotator cuff tissue has not been demonstrated. Timing to end conservative treatment is unknown, but likely indicated when a patient demonstrates increased weakness and loss of function not recoverable by physiotherapy.
\end{abstract}

KEY WORDS: natural history, physiotherapy, risk, rotator cuff.

\section{Introduction}

In the era of evidence-based medicine, many orthopaedic surgical disciplines are coming under increased scrutiny to provide data to support surgical intervention, and this is no less true for the shoulder surgeon. Some interventions have limited clinical evidence to support treatment options that are currently acceptable and available.

Rotator cuff disorders are common, accounting for up to $10 \%$ of all shoulder pain, and multiples of billions of dollars in overall costs for treatments of these conditions is spent the United States alone ${ }^{1}$. And yet today we still have limited and often-conflicting information concerning the natural history of rotator cuff tear and how it should be treated. Clinical assessment and monitoring of rotator cuff tears is also an area of debate. Since the known prevalence of asymptomatic rotator cuff tears is relatively high, it is legitimate to question how this impacts treatment and outcome ${ }^{2-5}$. Conservative treatment is often easily initiated, as it carries with it reasonable costs as compared to surgery, and an assumed low morbidity. In reality the 
picture is quite unclear and incomplete, as the number and quality of investigations for non-operative care is limited ${ }^{6-16}$. Understanding the true risk of non-operative care is very important in allowing for careful consideration of treatment options. Risks include tear progression, increase in pain severity, and further functional disability. The goals of this systematic review is to gain insight and assess the published literature in regards to the impact of non-operative interventions on the natural history of rotator cuff tears. Additionally, we aim to review of the risk of progression of rotator cuff tears and the impact on activities of daily living, as well as an attempt to define the risks of non-operative care. Finally, we aim to make a recommendation based on the evidence as to when a patient becomes an appropriate candidate for surgical intervention.

\section{Methods}

A comprehensive systematic review of the available literature in the English language was performed using PubMed, Cochrane Central Register of Controlled Trials, EMBASE and CINAHL searches (1 January 1960 - 1 December 2014). It was conducted and reported specifically by defining the study characteristics of interest, information sources, search strategy, selection strategy, data extraction, defining summary measures, and describing the methods of data handling. Because of the heterogeneity of the studies, combing results of the studies was not performed. All searches in all databases employed the search term combination(s): (rotator cuff tear and natural history/OR observation/OR injection/OR physiotherapy/OR physical therapy/OR corticosteroid/OR risk of conservative treatment/OR surgical indication/OR PRP/OR $\mathrm{MSC})$. The search was completed, independently, by two of the Authors in December of 2014. Initially, the abstracts were identified by title and compiled by the same two Authors independently (TAA and JPB). All methods used in this study meet the ethical standards of Muscles, Ligaments and Tendons Journal ${ }^{17}$.

\section{Study selection and data extraction}

After the provisional list of articles were identified and collected, they were reviewed according to the inclusion and exclusion criteria (Tab. 1), and the initial elimination process proceeded combining the search database results. These articles were downloaded directly from publishers or other online resources, and when not available, they were procured from local medical library or interlibrary loan. These were combined and reviewed by separate independent Author to verify the originality of the data, reducing the number to eleven articles (WDM) (Tab. 2).

\section{Quality assessment}

As most of the articles were of an experimental nature, the strength and quality of the evidence was determined using the validated modified Coleman Methodology Score ${ }^{18}$. A modification of this score was completed for use assessing conservative intervention by substituting surgical procedure with nonoperative procedure for the purposes of this study. There are 10 separate scoring domains that yield a minimum score of 0 and a maximum score of 100 (Tab. 3). Use of the Coleman Methodology Score modified for conservative therapy attempts to quantify the overall quality of methodology employed in an investigation and provide a relative value on a numerical scale. For purposes of this study the score was modified by substituting surgical interventions with conservative treatments, post-intervention rehabilitation and outcome measurement remained the same. The score is divided into Part A (7 subsections and only one score may be entered) and Part B (3 subsections and scores may be recorded for each option within each section). Part $A$ is scored by study size, mean follow-up, number of different conservative procedures included in each outcome, design of study, diagnostic certainty, description of conservative procedure given, description of postoperative rehabilitation. Part $B$ is divided into 3 subsections: 1) outcome

Table 1. Inclusion and exclusion criteria.

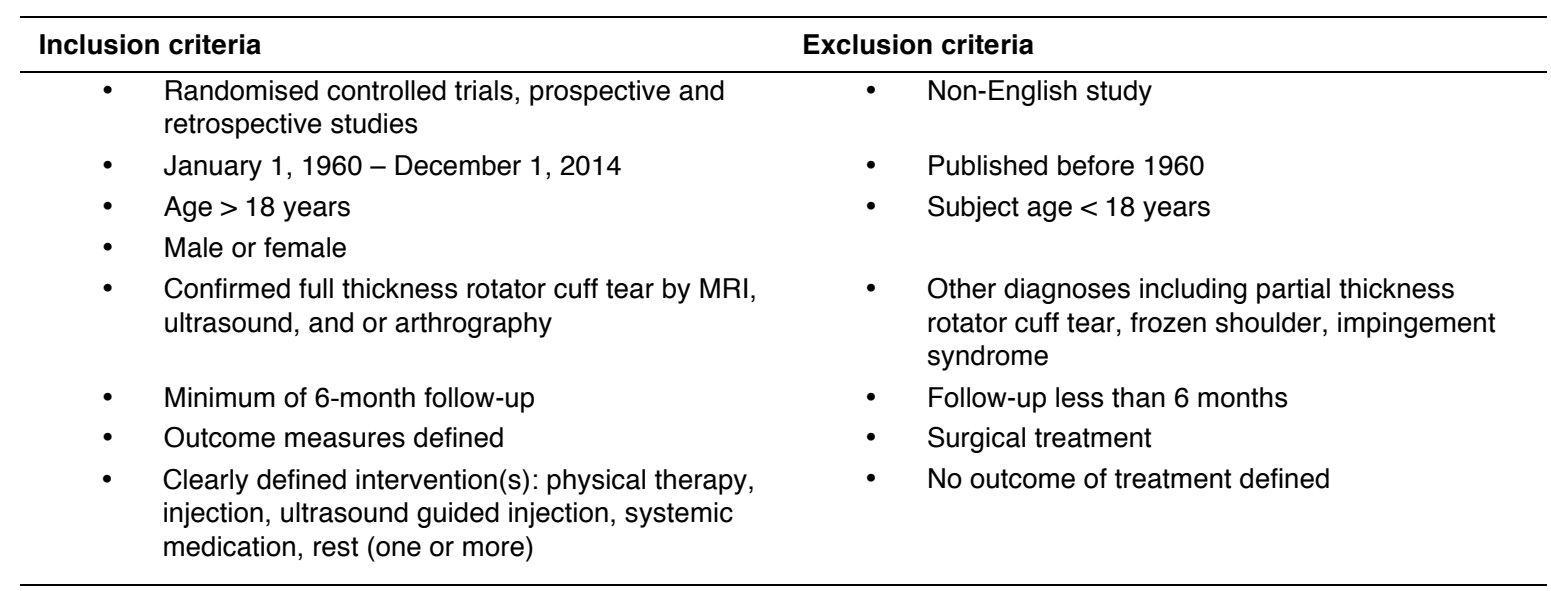


Table 2. Final article compilation list.

\begin{tabular}{|c|c|c|c|}
\hline Paper & Year & $\begin{array}{c}\text { Coleman Methodology Score- } \\
\text { Modified for Conservative } \\
\text { Therapy (CMS-MCT) } \\
\text { (Mean) }\end{array}$ & $\begin{array}{l}\text { Coleman Methodology Score- } \\
\text { Modified for Conservative } \\
\text { Therapy (CMS-MCT) }\end{array}$ \\
\hline Goldberg, et al. ${ }^{15}$ & 2001 & $\begin{array}{c}86 \text { (SD 2.16) } \\
(95 \% \text { Cl 80.67-91.36) }\end{array}$ & $88 / 83 / 87$ \\
\hline Shibata, et al. ${ }^{6}$ & 2001 & $\begin{array}{c}82 \text { (SD 2.16) } \\
(95 \% \mathrm{Cl} 76.64-87.36)\end{array}$ & $81 / 85 / 60$ \\
\hline Hawkins, et al. ${ }^{14}$ & 1995 & $\begin{array}{c}80 \text { (SD 4.32) } \\
(95 \% \text { Cl 69.27-90.73) }\end{array}$ & $78 / 78 / 86$ \\
\hline Kuhn, et al. ${ }^{9}$ & 2013 & $\begin{array}{c}78 \text { (SD 5.56) } \\
(95 \% \mathrm{Cl} 63.87-87.16)\end{array}$ & $80 / 83 / 70$ \\
\hline Gialanella, et al. ${ }^{8}$ & 2013 & $\begin{array}{c}75 \text { (SD 4.90) } \\
(95 \% \mathrm{Cl} 62.84-87.16)\end{array}$ & $81 / 69 / 75$ \\
\hline Costantino, et al. ${ }^{7}$ & 2009 & $\begin{array}{c}74 \text { (SD 4.19) } \\
(95 \% \mathrm{Cl} 63.27-84.07)\end{array}$ & $68 / 78 / 75$ \\
\hline Dunn, et al. ${ }^{12}$ & 2014 & $\begin{array}{c}65 \text { (SD 4.03) } \\
(95 \% \text { Cl 54.67-74.67) }\end{array}$ & $67 / 68 / 59$ \\
\hline Itoi, et al. ${ }^{16}$ & 1990 & $\begin{array}{c}62(\mathrm{SD} 4.19) \\
(95 \% \mathrm{Cl} 51.27-72.07)\end{array}$ & $66 / 63 / 58$ \\
\hline Brophy, et al. ${ }^{11}$ & 2014 & $\begin{array}{c}62 \text { (SD 3.40) } \\
(95 \% \text { Cl 53.90-70.77) }\end{array}$ & $59 / 61 / 67$ \\
\hline Unruh, et al. ${ }^{13}$ & 2013 & $\begin{array}{c}54 \text { ( SD 5.00) } \\
(95 \% \text { Cl 41.95-66.72) }\end{array}$ & $49 / 61 / 53$ \\
\hline Bokor, et al. ${ }^{10}$ & 1993 & $\begin{array}{c}44^{*}(\text { SD 13.70) } \\
(95 \% \text { Cl 30.32-59.01) }\end{array}$ & $69 / 57 / 40$ \\
\hline
\end{tabular}

Final score made by consensus.

criteria (outcome measures clearly defined, timing of outcome assessment is clearly stated, use of outcome criteria that has reported good reliability, use of outcome with good sensitivity); 2) procedure for assessing outcomes (subjects recruited, investigator independent of surgeon, written assessment, completion of assessment by subjects themselves with minimal investigator assistance); 3) description of subject selection process (selection criteria reported and unbiased, recruitment rate reported, eligible subjects not included in the study satisfactorily accounted for $100 \%$ recruitment). One independent, physiotherapist, rehabilitation physician, and orthopaedic surgeon scored all 11 included articles (HC, NBJ, and OV). Disagreement was defined as a score that was greater than 10 points from the mean of the overall score. Disagreement arose in one publication and a different physiotherapist, rehabilitation physician and orthopaedic surgeon who were blind to the initial results resolved the disagreement by consensus (AP, GAM, and SAT).

\section{Results}

The combined search resulted in 1785 citations. Included in this result are 2 systematic reviews previously performed, and bibliography review yielded 3 additional titles. After an initial screening was carried out 298 titles remained. Of the remaining titles, 57 duplicates were removed, and an additional 130 articles were eliminated, as they were not scientific investigations, leaving 111 abstracts assessed for eligibility. During secondary screening articles were removed for the following reasons: 33 treatment involved surgery, 41 did not involve any intervention, 10 had less than 20 patients, and 16 had less than 6 months of follow-up. Eleven studies that met all inclusion and exclusion criteria were finally included in this systematic review and outlined in the flowchart (Fig. 1) and extracted data (Tab. 4).

\section{Quality assessment}

The average Coleman Methodology Score modified 
Table 3. Description of the Coleman Methodology Score Modified for Conservative Therapy (CMS-MCT).

\begin{tabular}{|c|c|c|c|}
\hline & Domains & Subsection allocation & Score \\
\hline \multirow[t]{8}{*}{ Part A } & $\begin{array}{l}\text { Only one score to be given for } \\
\text { each of the seven sections }\end{array}$ & & \\
\hline & $\begin{array}{l}\text { 1. Study size: number of } \\
\text { patients }(\mathrm{N}) \text { (if multiple follow- } \\
\text { ups multiply } \mathrm{N} \text { by number of } \\
\text { times subjects followed up) }\end{array}$ & $\begin{array}{l}>60 \\
41-60 \\
20-40 \\
<20, \text { not stated }\end{array}$ & $\begin{array}{l}10 \\
7 \\
4 \\
0\end{array}$ \\
\hline & 2. Mean follow-up (months) & $\begin{array}{l}>24 \\
12-24 \\
<12, \text { not stated or unclear }\end{array}$ & $\begin{array}{l}5 \\
2 \\
0\end{array}$ \\
\hline & $\begin{array}{l}\text { 3. Number of different non- } \\
\text { operative interventions or } \\
\text { procedures included in each } \\
\text { reported outcome. More than } \\
\text { one non-operative interventions } \\
\text { or procedures may be } \\
\text { assessed but separated } \\
\text { outcomes should be reported }\end{array}$ & $\begin{array}{l}\text { One non-operative intervention only } \\
\text { More than one, but }>90 \% \text { subjects undergoing the one } \\
\text { intervention } \\
\text { Not stated, unclear, or }<90 \% \text { subjects undergoing the one } \\
\text { intervention }\end{array}$ & $\begin{array}{l}10 \\
7 \\
0\end{array}$ \\
\hline & 4. Type of study & $\begin{array}{l}\text { RCT } \\
\text { Prospective cohort } \\
\text { Retrospective cohort }\end{array}$ & $\begin{array}{c}15 \\
10 \\
0\end{array}$ \\
\hline & $\begin{array}{l}\text { 5. Diagnostic certainty (use of } \\
\text { pre-operative US, MRI) }\end{array}$ & $\begin{array}{l}\text { In all } \\
\text { In }>80 \% \\
\text { In }<80 \%\end{array}$ & $\begin{array}{l}5 \\
3 \\
0\end{array}$ \\
\hline & $\begin{array}{l}\text { 6. Description of non-operative } \\
\text { interventions or procedures } \\
\text { given }\end{array}$ & $\begin{array}{l}\text { Adequate (technique stated and necessary details given) } \\
\text { Fair } \\
\text { Inadequate, not stated }\end{array}$ & $\begin{array}{l}5 \\
3 \\
0\end{array}$ \\
\hline & $\begin{array}{l}\text { 7. Description of post- } \\
\text { intervention rehabilitation }\end{array}$ & $\begin{array}{l}\text { Well described with }>80 \% \text { of patients complying } \\
\text { Well described with } 60-80 \% \text { of patients complying } \\
\text { Protocol not reported or }<60-80 \%\end{array}$ & $\begin{array}{l}10 \\
5 \\
0\end{array}$ \\
\hline \multirow[t]{4}{*}{ Part B } & $\begin{array}{l}\text { Scores may be given for each } \\
\text { option in each of the three } \\
\text { sections if applicable }\end{array}$ & & \\
\hline & 1. Outcome criteria & $\begin{array}{l}\text { Outcome measures clearly defined } \\
\text { Timing of outcome assessments clearly stated (e.g., at best } \\
\text { outcome after initial intervention or at follow-up) } \\
\text { Use of outcome criteria that has good reliability } \\
\text { Use of outcome with good sensitivity }\end{array}$ & $\begin{array}{l}2 \\
2 \\
3 \\
3\end{array}$ \\
\hline & $\begin{array}{l}\text { 2. Procedure for assessing } \\
\text { outcomes }\end{array}$ & $\begin{array}{l}\text { Subjects recruited (results not take from surgeons' files) } \\
\text { Investigator independent of practitioner } \\
\text { Written assessment } \\
\text { Completion of assessment by the subjects themselves with } \\
\text { minimal investigator assistance }\end{array}$ & $\begin{array}{l}5 \\
4 \\
3 \\
3\end{array}$ \\
\hline & $\begin{array}{l}\text { 3. Description of subject } \\
\text { selection process }\end{array}$ & $\begin{array}{l}\text { Selection criteria reported and unbiased } \\
\text { Recruitment rate reported }>80 \% \text {; or }<80 \% \\
\text { Eligible subjects not included in the study satisfactorily } \\
\text { accounted for or } 100 \% \text { recruitment }\end{array}$ & $\begin{array}{l}5 \\
5 \\
3 \\
5\end{array}$ \\
\hline
\end{tabular}

for conservative therapy for all included papers is 69.21 (range 88-40) (SD 12.31) for the 11 included articles and overall the quality is in the poor range. There were no articles that were scored in the excellent range for study methodology (>90 points) $(0 / 11$ -
$0 \%) ; 3$ articles were scored in the good range $(<90$ but $>80$ points) $(3 / 11-27.30 \%) ; 3$ articles were scored in the fair range $(<80$ but $>70)(3 / 11-27.30 \%)$; and 5 articles were scored in the poor range ( $<70$ points) $(5 / 11-45.40 \%)$. A total of 10 areas are available for 


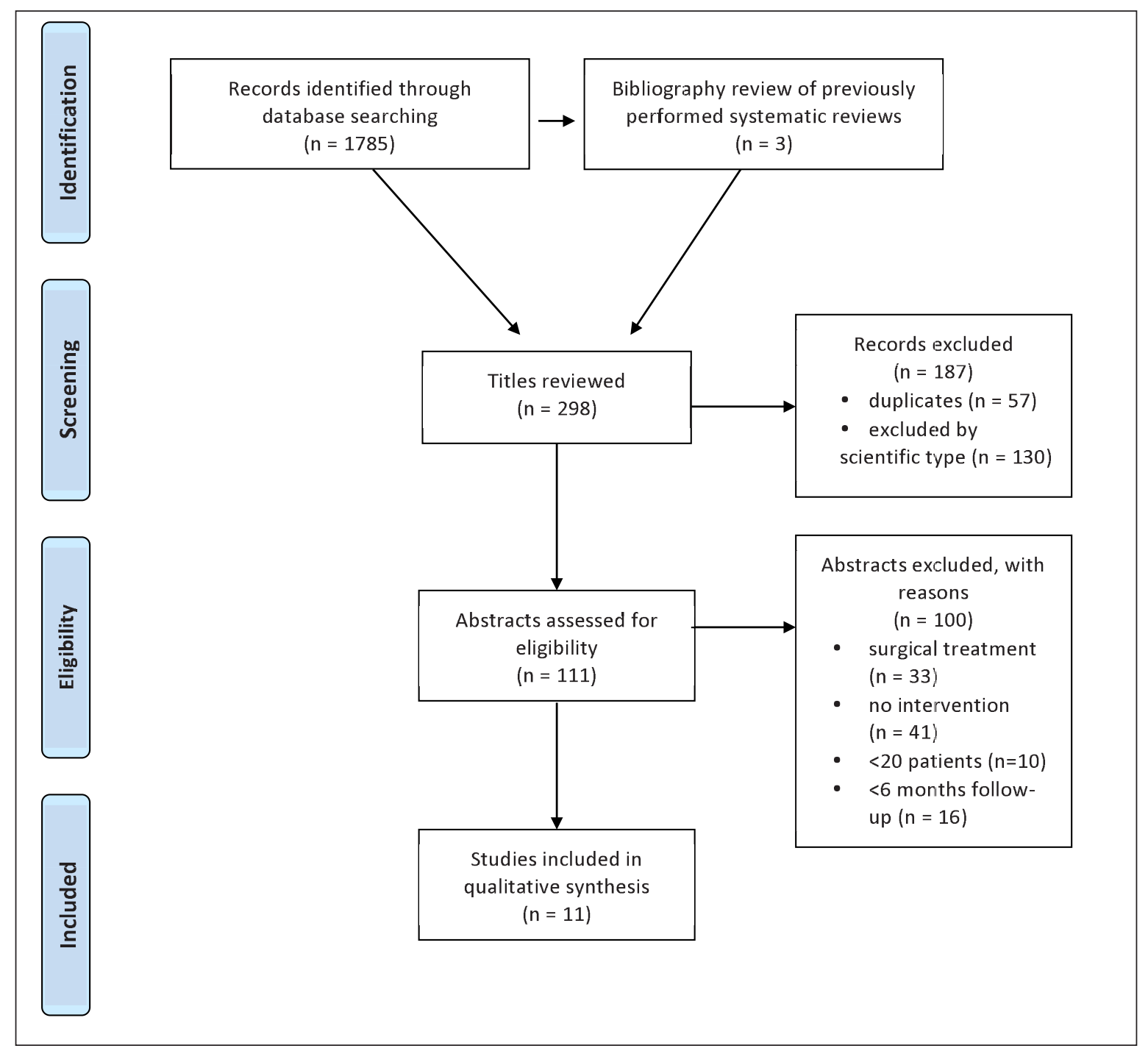

Figure 1. Flowchart of data identification and assessment.

scoring, 6 of which represent 75 of the possible 100 points. The type of study, description of subject selection process, procedure for assessing outcome, study size, single intervention utilised, and description of post-intervention rehabilitation. A perfect score in these 6 domains is critical for optimum quality score. The statistical analysis of Coleman Methodology Score modified for conservative therapy of the top 6 of 10 scoring domains of included articles (75\% points) (Tab. 5). The validated Coleman Methodology Score tool also lends itself to the assessment of risk of bias, and based on the overall score of included articles the risk of bias is considered high. Only two included articles were randomized control trials, neither blinded allocation, selection, treatment, or outcome assessment.

\section{Natural history of rotator cuff tears}

Knowledge of the natural history of rotator cuff tears is limited, and study methodology remains a problem including: limited follow-up, heterogenous patient diagnostic groups, and treatment and post-treatment rehabilitation interventions ${ }^{10-13,16}$. The data from 5 studies is included in this section. From a methodological stand point, data that could be evaluated to provide natural history information in the area of asymptomatic rotator cuff tears is limited largely to one cohort of patients ${ }^{11-13}$. The first study, a crosssectional study of 393 patients with symptomatic, atraumatic, full thickness rotator cuff tear demonstrated that rotator cuff severity did not correlate with pain ${ }^{12}$. Additionally, in a separate prospective cohort cross-sectional study of 450 patients with atraumatic, full-thickness rotator cuff tears found that longer duration of symptoms did not correlate with more severe rotator cuff disease, and was not related to outcome, fatty atrophy, tear size, limited range of motion, or weakness ${ }^{13}$. A different study, a retrospective cohort of 53 patients undergoing a myriad of conservative treatments in a heterogenous group of atraumatic, 


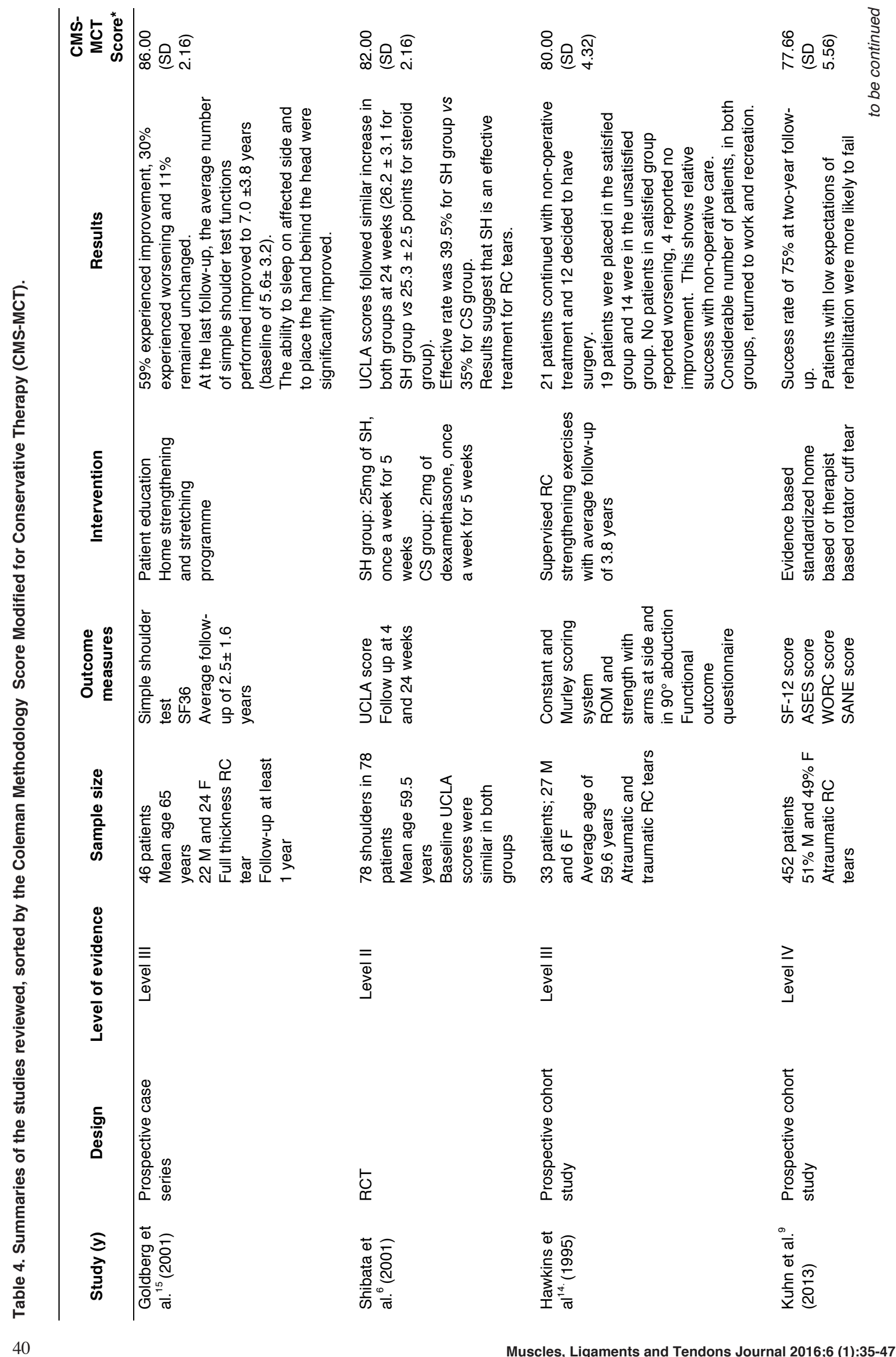




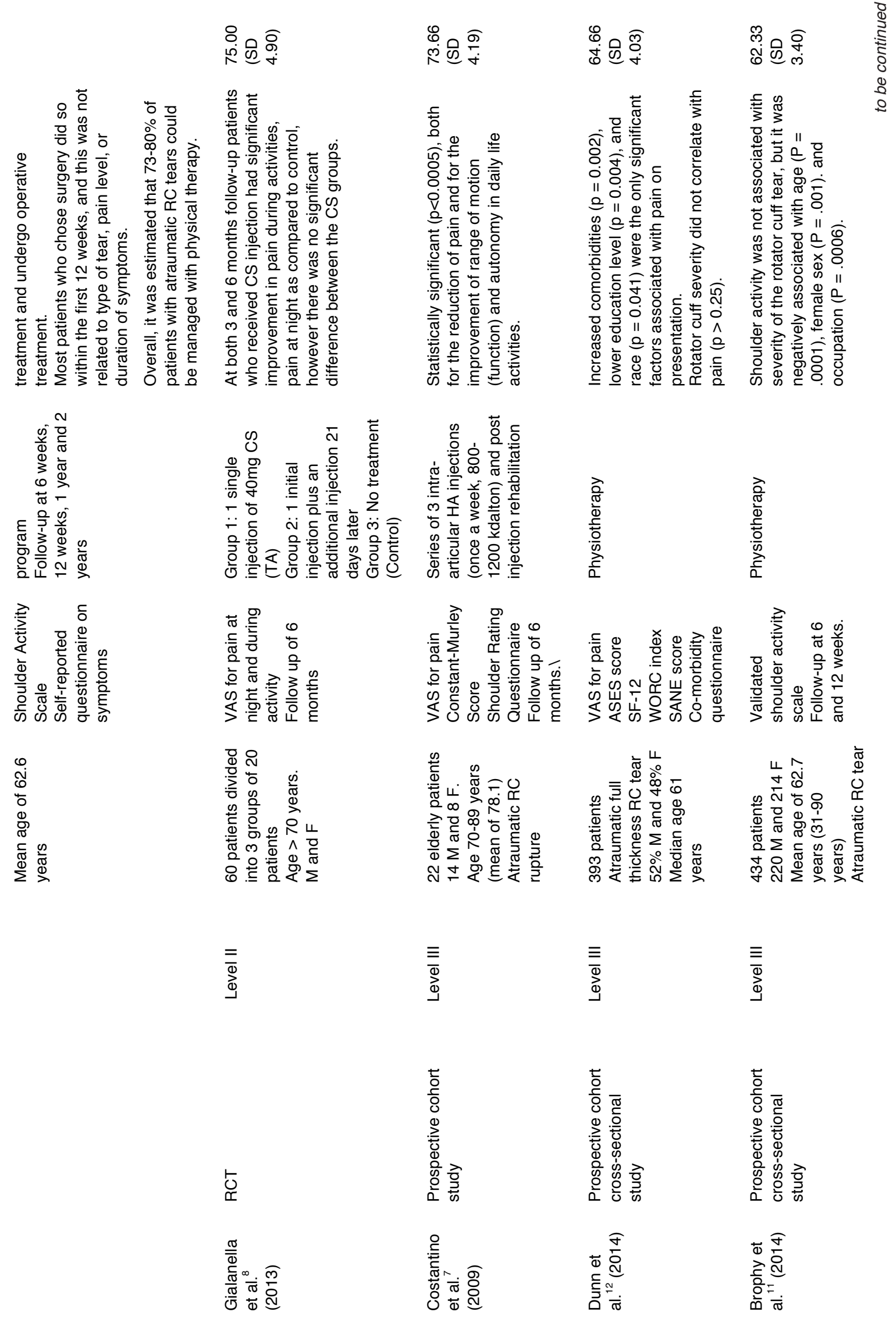



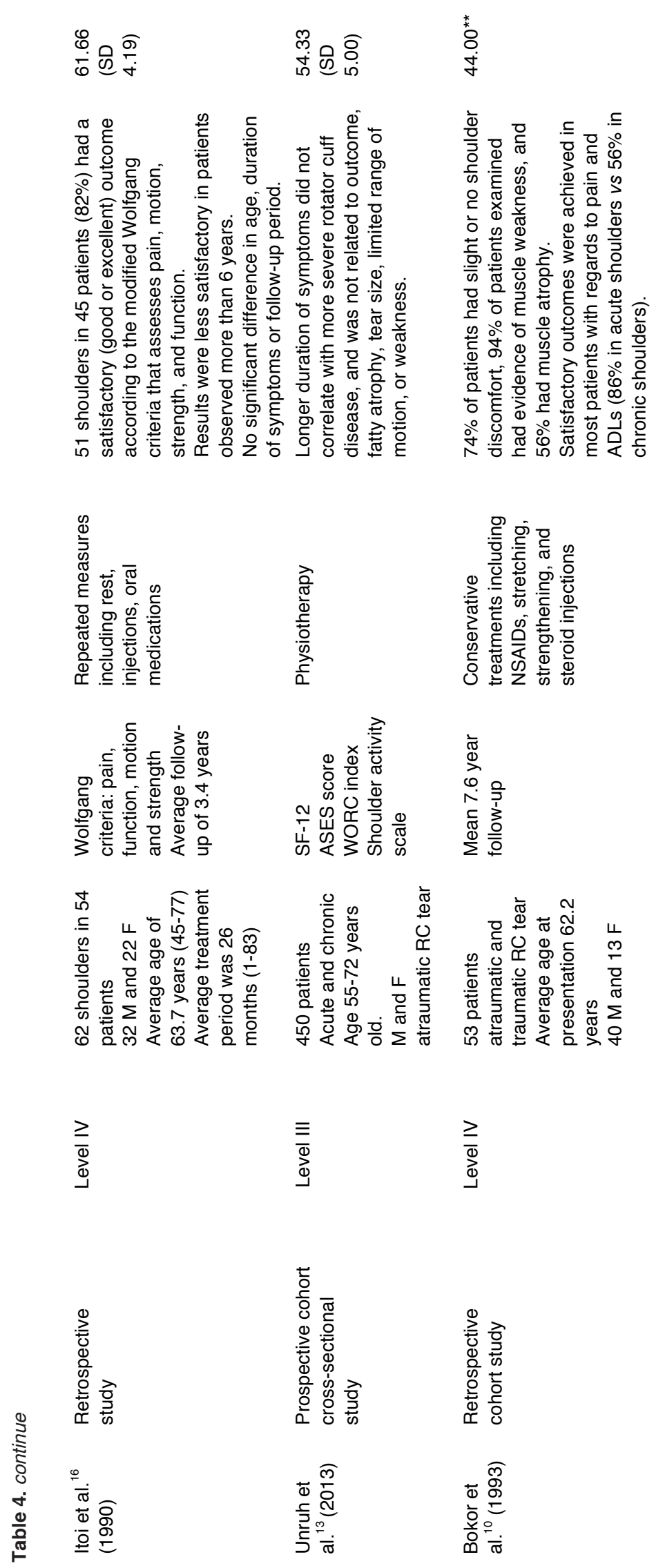

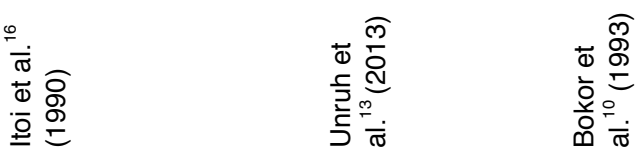


Table 5. Statistical analysis of Coleman Methodology Score modified for conservative therapy of the top 6 of 10 scoring domains of included articles $(75 \%$ of points).

\begin{tabular}{lcc}
\hline \multicolumn{1}{c}{ Domain } & Mean & Range \\
\hline Study size & 8.64 & $4-10$ \\
Study type & 9.70 & $0-15$ \\
$\begin{array}{l}\text { Subject selection } \\
\text { process described }\end{array}$ & 10.64 & $0-15$ \\
$\begin{array}{l}\text { Description of non- } \\
\text { operative interventions } \\
\text { given }\end{array}$ & 5.61 & $0-10$ \\
$\begin{array}{l}\text { Description of post- } \\
\text { intervention rehab }\end{array}$ & 5.45 & $0-10$ \\
$\begin{array}{l}\text { Procedure for assessing } \\
\text { outcomes }\end{array}$ & 10.91 & $3-15$ \\
\hline
\end{tabular}

traumatic rotator cuff tears with mean 7.60 year follow-up demonstrated that $74 \%$ of patients had slight or no shoulder discomfort, 32 of 34 patients examined $(94 \%)$ had evidence of muscle weakness, and 19 of 34 had muscle atrophy (56\%) however due to poor methodology any meaningful derived data is difficult at best ${ }^{10}$. Additionally, a different retrospective study of 62 shoulders in 54 patients treated with a variety of repeated measures including rest, injections, and oral medications with an average follow-up of 3.40 years demonstrated 51 shoulders in 45 patients (82\%) had a satisfactory (good or excellent) outcome according to the modified Wolfgang criteria that assesses pain, motion, strength, and function ${ }^{16}$. Patients who were followed for more than 6 years had significantly lower scores than those in the 1-3 and 36 year follow-up periods ${ }^{16}$.

\section{Physiotherapy/Rehabilitation of rotator cuff tears-} atraumatic

The use of physiotherapy as an intervention was found in 4 of the included 11 studies. An investigation of 452 patients, utilising an evidence based standardised home or therapist based rotator cuff tear program was effective in treating $75 \%$ of patients at $24-$ month follow-up 9 . The Authors noted that patients with low expectations of rehabilitation were more likely to fail treatment and undergo operative treatment. Most patients who chose surgery did so within the first 12 weeks, and this was not related to type of tear, pain level, or duration of symptoms. Overall it was estimated that $73-80 \%$ of patients with full thickness atraumatic rotator cuff tears could be managed with physical therapy. Patients that seemed to respond were those with no impingement signs, have good active external rotation, integrity of the intramuscular tendon of the supraspinatus, and little to no atrophy of the supraspinatus muscle ${ }^{9}$. In a separate study of 33 rotator cuff tears treated by standard re- habilitation protocol with a mean of 3.80 years followup reported $91 \%(10 / 11)$ success in terms of pain and outcome based on the Constant-Murley score in atraumatic rotator cuff tears group included in the cohort ${ }^{15}$.

\section{Physiotherapy/Rehabilitation of rotator cuff tears-trau-} matic

Traumatic rotator cuff tears is another area of interest. Nonetheless, the natural history is probably under reported as in many cases acute traumatic tears are probably repaired versus treated conservatively. In our review, one paper was identified that was a mixture of traumatic (22/33) and atraumatic rotator cuff tears $(11 / 33)^{15}$. A standard rehabilitation program was utilized and $68 \%(15 / 22)$ at 3.80 years follow-up did not undergo surgery, and $67 \%(10 / 15)$ in the nonsurgical group had a good or excellent result based on improved pain and/or improved outcome based on the Constant-Murley score ${ }^{15}$.

\section{Systemic medications for treatment of rotator cuff} tears

Currently, no study or trial has been conducted for the purposes of evaluating NSAIDs or other analgesics specifically for efficacy in treatment of rotator cuff tears. Only investigations for shoulder pain in general have been conducted.

\section{Injection for treatment of rotator cuff tears}

Three studies met inclusion criteria and were included in this review. All studies utilized a blind technique for injection into the glenohumeral joint. A trial of 78 shoulders in 78 patients with full-thickness tears compared corticosteroid (CS) (mean age 62.40 years) versus sodium hyaluronate (HA) (mean age 59.50 years) injections (5 injections over 5 consecutive weeks) at 4 weeks following treatment, $42 \%$ in the HA group and $37.50 \%$ in the CS group were satisfied with the treatment, and the effects were durable, with $40 \%$ and $35 \%$ satisfaction in $\mathrm{HA}$ and CS groups respectively at 24 -week post-treatment ${ }^{6}$. Costantino et al. (2009), prospectively evaluated the use of a series of 3 intra-articular HA injections and post injection rehabilitation in 22 elderly patients who had follow-up evaluations at 3 and 6 months ${ }^{7}$. Significant improvement was seen at 6 months in terms of VAS, Constant-Murley Score, and Shoulder Rating Questionnaire translating to improvement in pain, function, and quality of life. It is not clear if the results of this study are a result of the rehabilitation program, HA, or both 7 . A different study, a RCT comprised of $60 \mathrm{el}-$ derly patients that evaluated the effect of intra-articular CS injection into the glenohumeral joint that was divided into 3 groups of 20 patients $^{8}$. Group 1 received a single injection of CS, group 2 received the initial injection plus an additional injection 21 days later, and group 3 was the control. At both 3 and 6 months follow-up patients who received CS injection had significant improvement in pain during activities, pain at night as compared to control, however there was no difference between the CS groups ${ }^{8}$. 
Biologics injection for treatment of rotator cuff tears No study or trial has been conducted for the purposes of evaluating the injection of biological substances such as platelet rich plasma (PRP), bone marrow aspirate concentrate (BMAC), or mesenchymal stem cells (MSCs) for the specific treatment of full-thickness rotator cuff tears primarily.

\section{Discussion}

\section{Natural history of rotator cuff tears}

Investigations concerning the natural history of rotator cuff tears is limited and often times conflicting; compounding the problems are the methodological variability especially in reference to post treatment assessment, outcome measurement, and single intervention being evaluated. In the case of single intervention evaluation, many publications report on the effects of two or more interventions at once, this makes it very difficult to ascertain any effects of treatment. Despite the short-comings of available data reviewed in this report, one consistent theme is that prevalence of full thickness rotator cuff tears is common, and that symptoms are quite individualised, and that duration of tears, and tear size do not necessarily correlate with symptoms ${ }^{11-13}$. This is also highlighted by other studies of asymptomatic rotator cuff tears in the literature. One such ultrasound investigation in 411 volunteers over the age of 50 years found the overall prevalence of asymptomatic full-thickness tears to be $13 \%$ overall, and $51 \%$ in subjects over 80 years old ${ }^{3}$. In contrast, a longitudinal prospective analysis demonstrated the progressive nature of degenerative rotator cuff disease in shoulders with asymptomatic tears ${ }^{19}$. The risk of tear enlargement is greater for shoulders with more advanced tears and is associated with a greater risk of cuff muscle degenerative changes. This group reported that tear enlargement is also associated with greater risks of pain development across all tear types $(50 \% \text { for full-thickness tears })^{19}$. A separate publication from the same institution reported on a series of 588 consecutive patients demonstrated that larger tears were more likely to be symptomatic; additionally, those who presented with a symptomatic tear on one side, had an incidence of $35.50 \%$ contralateral asymptomatic full-thickness tears ${ }^{20}$. However both the preceding reports are in conflict with cross-sectional studies reviewed in this report on the non-operative treatment of symptomatic full-thickness rotator cuff tears by the MOON group on tear size and symptoms, but are consistent with these studies for the presence and prevalence of asymptomatic tears ${ }^{11-13}$. The methodological quality of the studies reviewed are in poor range ( $<70 / 100$ points) and this must not temper any firm conclusions at this point. Another report of 45 consecutive patients diagnosed with symptomatic full-thickness tears and contralateral asymptomatic full-thickness tears were followed by ultrasound over a fiveyear period, from 1989 to $1994^{21}$. Twenty-three of the 45 patients responded to a request to complete an evaluation and outcome questionnaire, with 23 patients agreeing to undergo repeat ultrasound evaluation. Twenty-three $(51 \%)$ of these patients became symptomatic by a mean time of 2.8 years. However, the symptoms were mild to moderate. Nine (39\%) of the 23 demonstrated tear progression. The Authors concluded that there appears to be a risk of tear progression over time in bilateral rotator cuff tears, but possibly what this could mean is that over time symptoms can be progressive, and not necessarily due to tear size or progression ${ }^{21}$. Another comparison natural history to the results of our review is the study of 59 shoulders in 54 patients with a mean age of 58.80 years diagnosed by $\mathrm{MRI}$ and managed conservative$\mathrm{ly}^{22}$. The group was retrospectively studied and demonstrated 33 full-thickness tears, 26 partial thickness rotator cuff tear (PTT), and 4 combined tears. Progression in tear size was observed more often in subjects followed for more than 18 months. Seventeen of $33(52 \%)$ full-thickness tears, and 2 of the 26 PTT progressed in tear size. Factors that were associated with progression of rotator cuff tears were age greater than 60 years, full-thickness tears, and fatty infiltration of muscle 22 . Mall et al. (2010), compared asymptomatic and symptomatic rotator cuff tears, determining that many with asymptomatic full-thickness tears will develop symptoms with time ${ }^{23}$. In the study, this was largely seen with larger tears and required significant time for progression to occur, and for glenohumeral and scapular mechanical dysfunction to become apparent. Only a very small percentage of asymptomatic and symptomatic tears both at initial and at two year follow-up demonstrated fatty degeneration in this study. This fact allays the concern of risk in conservative management ${ }^{23}$. Safran et al. (2011), investigated non-operative treatment in symptomatic full-thickness tears in patients 60 years or younger by sequential bilateral ultrasound examination ${ }^{24}$. Of the 61 initial tears at mean 29 months follow-up, it was found that $49 \%$ (30 tears) increased in size, 43\% (26 tears) had not changed, and $8 \%$ (5 tears) had decreased in size. Symptom severity correlated significantly with an increase in tear size ${ }^{24}$.

\section{Physiotherapy/rehabilitation of rotator cuff tears- atraumatic/traumatic}

The methodology for the single mixed study of atraumatic and traumatic rotator cuff tears reported is in the good range ( $>80$ but $<90$ points), demonstrating relative success over time utilising non-operative treatment, however data is limited to a single study with limited numbers of subjects ${ }^{14}$. Available comparison for the non-operative treatment of acute full thickness rotator tears again is quite limited. One study of 104 patients with a median age of 49 (19-75 years) was evaluated by ultrasound within 50 days of shoulder injury, revealing 33 patients (32\%) with full-thickness tears ${ }^{25}$. The prevalence increased to above $50 \%$ in patients over 50 years. At one year follow-up of the 75 patients receiving conservative treatment, of the 10 patients available for review that were initially di- 
agnosed with full-thickness tears; 1 tear was unchanged, 2 tears had decreased in size (both younger patients), and 5 tears had increased in size and had occasional symptoms. Only one went on to surgery, and 2 tears were unreported 25

\section{Physiotherapy/rehabilitation of rotator cuff tears- atraumatic}

Physiotherapy is a very common treatment intervention for pain and disability related to full-thickness tears. In this review, a limited number of studies with a range of poor to good methodology, makes it very difficult to truly assess the evidence. The major shortcomings of the reviewed studies were either that they were retrospective, or had an unclear patient selection process; intervention was not clearly defined, and lacked post intervention rehabilitation description ${ }^{11-13}$. The current review has seen progression in the quality of studies reported with 2 randomised controlled trials included to date, compared to a previous systematic review from 2007 where no randomised controlled trial was completed at that time ${ }^{26}$. Most studies in the 2007 review were case series or observational studies, and because of data heterogeneity the studies, the Authors were unable to combine data for analysis. In addition, there were only four trials that looked at exercise therapy alone. The results suggest that exercise therapy that consists of strengthening and stretching is beneficial for symptomatic shoulders with full-thickness tears. However, at best, the true effect due to the combination of interventions cannot be determined ${ }^{26}$. An earlier systematic review investigated physiotherapy regimes of the rotator cuff in adults and concluded there was a complete lack of evidence for any intervention in the treatment of full-thickness tears ${ }^{27}$. The Authors did not show any improvement, as compared to placebo, for physiotherapy in the studies reviewed, and there was little evidence to support or refute the efficacy of treatment, except on the basis of cost and minimal invasiveness ${ }^{27}$. As reviewed in our study, the MOON group study's methodology was in the fair range, a multi-centre prospective cohort study utilizing a validated physical therapy regimen for the treatment of atraumatic rotator cuff tears in 452 patients, and reported a success rate of $75 \%$ at two year follow-up ${ }^{9}$. In the future, adequately powered randomised controlled trials may help bring clarity to this area of debate.

\section{Systemic medications for treatment of rotator cuff tears}

For treatment of rotator cuff tears with systemic medications, only general studies for shoulder pain have been conducted. The highest quality studies showed superior short-term efficacy as compared to placebo, however many of the randomised controlled trials for treatment of shoulder pain have limited numbers of patients, focus on heterogenous conditions, have minimal comparisons to placebo, most have a followup of four weeks or less, and only a few have a 6-8 month follow-up ${ }^{28}$. The chronic use of NSAIDs has been associated with many problems. COX-2 inhibitors have also shown short-term efficacy in clinical trials for shoulder pain and in meta-analysis and systematic review ${ }^{29}$. However, efficacy should be balanced with the considerable risks, including gastrointestinal bleeding, hepatic dysfunction, renal impairment, in both the short and long-term and duration of treatment directly impacts on the risk of death and cardiac events ${ }^{29}$

\section{Injection for treatment of rotator cuff tears}

Despite the common practice of administration of CS during non-operative management of full thickness rotator cuff tears, only one trial specifically looked at the efficacy of CS injection in the treatment of fullthickness tears, and was included in this systematic review $^{8}$. The methodology for this study was fair ${ }^{8}$. With limited numbers of studies for comparison, small sample sizes, and heterogenous treatment regimens and diagnosis, it is difficult to draw conclusions and/or make recommendations concerning the use of CS in the management of full-thickness tears based on published evidence. The requirement for further study is warranted by investigations that clearly define the diagnosis, randomisation of treatment(s) versus control, use of specific validated outcome measures, and the time intervals of assessment to measure the effects of treatment ${ }^{30}$. For the use of hyaluronic acid, two studies were reviewed demonstrating fair to good methodology ${ }^{6,7}$. In comparison with the use of $\mathrm{HA}$ in other investigations, a randomised, controlled, multi-centre trial using HA versus phosphate buffered saline to treat shoulder pain in 667 subjects $^{31}$. Although many of the patients had osteoarthritis of the shoulder, some of the $66 \%$ patients had partial or full-thickness tears, and/or adhesive capsulitis ${ }^{31}$. The study demonstrated that the HA groups had more significant pain relief than controls at 7 weeks, 17 weeks, and 28 weeks $^{31}$. This comparison again highlights the overall lack of data, and therefore little inference can be made.

\section{Biologics injection for treatment of rotator cuff tears}

As previously stated in the results, there has not been any published report on the effectiveness of PRP or MSC use in the primary treatment of rotator cuff tear. Reports have been limited to treatment of tendinopathy and or partial rotator cuff tear ${ }^{32-34}$. Hopefully in the future, more investigations will provide needed data to evaluate this treatment.

\section{Risks of conservative treatment rotator cuff tears}

The commonly discussed risks of conservative treatment in full-thickness tears include: tissue damage with repeated corticosteroid injection, progression of tear size, and the induction of irreversible and irreparable rotator cuff changes that could impact the 
ultimate outcome of surgical repair. There were no studies for this review that met inclusion criteria, and therefore no conclusions can be drawn.

Risk associated with repeated corticosteroid injection in full-thickness tears is unknown, as most of the data available concerns use in earlier stages of rotator cuff disease. Corticosteroid injections have been found to damage collagen and healing response in animal studies precipitating rotator cuff tears ${ }^{35}$. However, in humans, reports of softening of the rotator cuff tissue and the effects on repair have most often been demonstrated in uncontrolled studies, and anecdotal case series and reports ${ }^{36-39}$. Nevertheless further study of this possible risk factor is relevant, and hopefully will be addressed in the future.

\section{Indications to transition from conservative to sur- gical treatment}

Unfortunately there are no clear indications or recommendations to proceed from nonoperative care to surgery based on evidence. Kuhn et al. (2013), in post-hoc analysis found that in atraumatic rotator cuff tear subjects who did not believe therapy would be successful failed conservative therapy a majority of the time $^{9}$. Classically, some of the clinical indicators to proceed to surgical therapy used in the past include traumatic tear, symptomatic full-thickness tear in patients who have failed conservative therapy for at least six weeks, physiologically young patients, patients with full passive range of motion, and patients with a requirement for overhead activity. The best available evidence suggests earlier surgical intervention may be indicated in patients with functional disability and weakness ${ }^{40}$. A further coordinated and defined study is required in the future.

The strengths of this investigation is that this systematic review was inclusive of all data types and assessed a broad number of treatments for full-thickness rotator cuff tears using a validated assessment tool for gauging the quality of study methodology. The study outlined both topics, as well as areas to improve the methodology for future studies that will hopefully result in more conclusive data. The weaknesses of the review is clearly the paucity of available studies, the inability to combine results due to extreme heterogeneity of investigations, variability of scoring using the instrument, and the lack of true data synthesis.

\section{Conclusion}

In summary, although the body of evidence is limited and exhibits heterogeneity, the trends in available data suggest that monitored conservative treatment of rotator cuff tears is probably safe and without significant risk and morbidity, and can be successful in more patients than previously believed. Improvement of study methodology in the following areas: the use of randomised controlled trials, subject selection process, description(s) of intervention(s), description of post-intervention rehabilitation, and the process for assessing outcome will result in higher quality data to help direct clinical practice in the future. Conservative therapy including injections of all varieties, and physiotherapy can probably be used safely with appropriate monitoring. Although there is considerable interest concerning the use of biologicals such as PRP for rotator cuff tears at this time, outcome and effective data is lacking at the moment ${ }^{41-43}$. The indication for proceeding with operative treatment is probably best suggested for patients who do not believe physiotherapy will work for them, and those that demonstrate significant weakness and physical impairment. Rotator cuff size, progression of tear, and pain severity should not have significant impact on intermediate term outcome, however additional higher quality data is warranted. The future performance of comprehensive, well-designed clinical trials are required, to solidify recommendations for both non-operative as well as operative treatment for full thickness rotator cuff tear $^{44-46}$.

\section{Conflict of interests}

The Authors declare that they have no conflict of interests regarding the publication of this paper.

\section{References}

1. Meislin RJ, Sperling JW, Stitik TP. Persistent shoulder pain: epidemiology, pathophysiology, and diagnosis. Am J Orthop. 2005;34(12 suppl):5-9.

2. Milgrom C, Schaffler M, Gilbert S, van Holsbeeck M. Rotatorcuff changes in asymptomatic adults. The effect of age, hand dominance and gender. J Bone Joint Surg Br. 1995;77(2):296298.

3. Tempelhof S, Rupp S, Seil R. Age-related prevalence of rotator cuff tears in asymptomatic shoulders. J Shoulder Elbow Surg. 1999;8(4):296-299.

4. Yamamoto A, Takagishi K, Osawa T, et al. Prevalence and risk factors of a rotator cuff tear in the general population. J Shoulder Elbow Surg. 2010;19(1):116-120.

5. Moosmayer S, Tariq R, Stiris M, Smith HJ. The natural history of asymptomatic rotator cuff tears: a three-year follow-up of fifty cases. J Bone Joint Surg Am. 2013;95(14):1249-1255.

6. Shibata Y, Midorikawa K, Emoto G, Naito M. Clinical evaluation of sodium hyaluronate for the treatment of patients with rotator cuff tear. J Shoulder Elbow Surg. 2001;10(3):209-216.

7. Costantino $\mathrm{C}$, Ovirri S. Rehabilitative and infiltrative treatment with hyaluronic acid in elderly patients with rotator cuff tears. Acta Biomed. 2009;80(3):225-229.

8. Gialanella B, Bertolinelli B. Corticosteroids injection in rotator cuff tears in elderly patient: Pain outcome prediction. GeriatrGerontol Int. 2013;13(4):993-1001.

9. Kuhn JE, Dunn WR, Sanders R, et al. Effectiveness of physical therapy in treating atraumatic full-thickness rotator cuff tears: a multicenter prospective cohort study. J Shoulder Elbow Surg. 2013;22(10):1391-1379.

10. Bokor DJ, Hawkins RJ, Huckell GH, Angelo RL, Schickendantz MS. Results of nonoperative management of full-thickness tears of the rotator cuff. Clin Orthop Relat Res. 1993; 294:103-110.

11. Brophy RH, Dunn WR, Kuhn JE and MOON Shoulder Group. 
Shoulder activity is not associated with the severity of symptomatic, atraumatic rotator cuff tears in patients electing nonoperative treatment. Am J Sports Med. 2014;42(5):1150-1154.

12. Dunn WR, Kuhn JE, Sanders RS, et al. Symptoms of pain do not correlate with rotator cuff severity. J Bone Joint Surg Am. 2014;96(10):793-800.

13. Unruh KP, Kuhn, JE, Sanders $R$, et al. The duration of symptoms does not correlate with rotator cuff severity or other patient-related features: a cross-sectional study of patients with atraumatic, full-thickness rotator cuff tears. J Shoulder Elbow Surg. 2014;23(7):1052-1058.

14. Hawkins RH, Dunlop R. Nonoperative treatment of rotator cuff tears. Clin Orthop Relat Res. 1995;321:178-188.

15. Goldberg BA, Nowinski RJ, Matsen FA. Outcome of nonoperative management of full-thickness rotator cuff tears. Clin Orthop Relat Res. 2001;382:88-107.

16. Itoi E, Tabata S. Conservative treatment of rotator cuff tears. Clin Orthop Relat Res. 1992;275:165-173.

17. Padulo J, Oliva F, Frizziero A, Maffulli N. Muscles, Ligaments and Tendons Journal. Basic principles and recommendations in clinical and field science research. MLTJ. 2013;3(4):250-252.

18. Coleman BD, Khan KM, Maffulli N, Cook JL, Wark JD. Studies of surgical outcome after patellar tendinopathy: clinical significance of methodological deficiencies and guidelines for future studies. Scand J Med Sci Sports. 2000;10(1):2-11.

19. Keener JD, Galatz LM, Teefey SA, et al. A prospective evaluation of survivorship of asymptomatic degenerative rotator cuff tears. J Bone Joint Surg Am. 2015;97(2):89-98.

20. Yamaguchi K, Ditsios K, Middleton WD, Hildebolt CF, Galatz LM, Teefey SA. The demographic and morphological features of rotator cuff disease. A comparison of asymptomatic and symptomatic shoulders. J Bone Joint Surg Am. 2006;88 (8):1699-1704.

21. Yamaguchi K, Tetro AM, Blam O, Evanoff BA, Teefey SA, Middleton WD. Natural history of asymptomatic rotator cuff tears: a longitudinal analysis of asymptomatic tears detected sonographically. J Shoulder Elbow Surg. 2001;10(3):199-203.

22. Maman E, Harris C, White L, Tomlinson G, Shashank M, Boynton E. Outcome of nonoperative treatment of symptomatic rotator cuff tears monitored by magnetic resonance imaging. J Bone Joint Surg Am. 2009;91(8):1898-1906.

23. Mall N, Kim H, Keener J, et al. Symptomatic Progression of Asymptomatic Rotator Cuff Tears: a prospective study of clinical and sonographic variables. J Bone Joint Surg Am. 2010; 92(16):2623-2633.

24. Safran O, Schroeder J, Bloom R, Weil Y, Milgrom C. Natural history of nonoperatively treated symptomatic rotator cuff tears in patients 60 years old or younger. Am J Sports Med. 2011; 39(4):710-714

25. Sørensen AK, Bak K, Krarup AL, et al. Acute rotator cuff tear: Do we miss the early diagnosis? a prospective study showing a high incidence of rotator cuff tears after shoulder trauma. $J$ Shoulder Elbow Surg. 2007;16(2):174-180.

26. Ainsworth R, Lewis J. Exercise therapy for the conservative management of full thickness tears of the rotator cuff: a systematic review. Br J Sports Med. 2007;41(4):200-210.

27. Ejinsman B, Andreoli C, Soares B, et al. Interventions for tears of the rotator cuff in adults. Cochrane Database Syst Rev. 2004;(1):CD002758.

28. van der Windt DA, van der Heijden GJ, Scholten RJ, Koes BW, Bouter LM. The efficacy of non-steroidal anti-inflammatory drugs (NSAIDS) for shoulder complaints. A systematic review. J Clin Epidemiol. 1995;48(5):691-704.
29. McGettigan P, Henry D. Cardiovascular Risk with NonSteroidal Anti-Inflammatory Drugs: Systematic Review of Population- Based Controlled Observational Studies. PLos Med. 2011;8(9):e1001098.

30. Weiss J. Intra-articular steroids in the treatment of rotator cuff tear: reappraisal by arthrography. Arch of Phys Med Rehabil. 1981;62(11):555-557.

31. Blaine, T, Moskowitz R, Udell J, et al. Treatment of persistent shoulder pain with sodium hyaluronate: A randomized, controlled trial. J Bone Joint Surg Am. 2008;90(5):970-979.

32. Kesikburun S, Tan AK, Yilmaz B, Yasar E, Yazicioglu K Platelet-rich plasma injections in the treatment of chronic rotator cuff tendinopathy: a randomized clinical trial with 1-year follow-up. Am J Sports Med. 2013;41(11):2609-2616.

33. Rha DW, Park GY, Kim YK, Kim MT, Lee SC. Comparison of the therapeutic effects of ultrasound-guided platelet-rich plasma injection and dry needling in rotator cuff disease: a randomized controlled trial. Clin Rehabil. 2013;27(2):113-122.

34. Scarpone M, Rabago D, Snell E, et al. Effectiveness of platelet-rich plasma injection for rotator cuff tendinopathy: a prospective open-label study. Glob Adv Health Med. 2013;2 (2):26-31.

35. Akpinar S, Hersekli MA, Demirors H, Tandogan RN, Kayaselcuk $F$. Effects of methylprednisolone and betamethasone injections on the rotator cuff: an experimental study in rats. Adv Ther. 2002;19(4):194-201.

36. Blair B, Rokito AS, Cuomo F, Jarolem K, Zuckerman JD. Efficacy of injections of corticosteroids for subacromial impingement syndrome. J Bone Joint Surg Am. 1996;78(11):16851689.

37. Bhatia M, Singh B, Nicolaou N, Ravikumar KJ. Correlation between Rotator Cuff Tears and Repeated Subacromial Steroid Injections: A Case Controlled Study. Ann R Coll Surg Engl. 2009;91(5):414-416.

38. Ramirez J, Pomes I, Cabrera S, Pomes J, Sanmarti R, Canete JD. Incidence of full-thickness rotator cuff tear after subacromial corticosteroid injection: A 12-week prospective study. Mod Rheumatol. 2014;24(4):667-670.

39. Watson M. Major ruptures of the rotator cuff. The results of surgical repair in 89 patients. J Bone Joint Surg Br. 1985;67 (4):618-624.

40. Oh LS, Wolf BR, Hall MP, Levy BA, Marx RG. Indications for rotator cuff repair: a systematic review. Clin Orthop Relat Res. 2007;455:52-63.

41. Giai Via A, De Cupis M, Spoliti M, Oliva F. Clinical and biological aspects of rotator cuff tears. Muscles Ligaments Tendons J. 2013;3(2):70-79. Erratum in: Muscles Ligaments Tendons J. 2014;3(4):359.

42. Oliva F, Giai Via A, Maffulli N. Role of growth factors in rotator cuff healing. Sports Med Arthrosc. 2011;19(3):218-226.

43. Castagna A, Cesari B, Gerofalo R, et al. Matrix metalloproteases and their inhibitors are altered in torn rotator cuff tendons, but also in the macroscopically and histologically intact portion of those tendons. Muscles Ligaments Tendons $\mathrm{J}$. 2013;3(3):132-138.

44. Merolla G, Paladini P, Saporito M, Porcellini G. Conservative management of rotator cuff tears: literature review and proposal for a prognostic prediction score. Muscles Ligaments Tendons J. 2011;1(1):12-19.

45. Oliva F, Piccinilli E, Bossa M, et al. I.S.Mu.L.T - Rotator Cuff Tears Guidelines. MLTJ. 2015;5(4): 227-263.

46. Oliva F, Piccinilli E, Berardi AC, Frizziero A, Tarantino U, Maffulli N. Hormones and tendinopathies: the current evidence. $\mathrm{Br}$ Med Bull. 2016. 